\title{
Ship Block Logistics Simulation Based on Discrete Event Simulation
}

\author{
http://dx.doi.org/10.3991/ijoe.v11i6.4968 \\ Chong Wang*, Yun-sheng Mao, Zu-quan Xiang, Yong-qing Zhou \\ Wuhan University of Technology, Wuhan, China
}

\begin{abstract}
The load of resources in the block logistics process influences the mid-term planning and scheduling of shipyard management. Therefore, load analysis must be conducted before confirming the plans. However, conducting the analysis using the traditional mathematical model is difficult. This study suggests using the discrete event simulation (DES) method for load analysis in advance. The simulation model of actual shipyard block logistics is established by the DES software. Data on the structure of the product, process, resource, and schedule are clearly defined to match the DES model. Partial results through the simulation are discussed in terms of real production activities. The outputs prove that the proposed simulation model can help planners arrive at reasonable and rational decisions related to shipbuilding plans. This simulation method can contribute in strengthening the competitiveness of shipyards.
\end{abstract}

Index Terms-Discrete Event Simulation, Block Logistics Simulation, Shipbuilding

\section{INTRODUCTION}

The shipbuilding industry is facing the complex and multifaceted problem of low demand and excessive production capacity as a result of the global economic crisis and global shipping market slump. In particular, the human and material costs have risen sharply in the Chinese shipbuilding market. Given these difficult situations, the surviving shipyards are making every effort to strengthen their ability to improve their management and productivity using new technologies. All kinds of supporting technologies are being studied such as information technology, Internet of things, digital shipbuilding system, product lifecycle management, virtual manufacturing and modeling and simulation $(\mathrm{M} \& \mathrm{~S})$.

Lee et al. (2014) concluded that the six key factors of shipyard productivity are product, process, facility, space, human, and scheduling. Among these factors, facility, space, human, and scheduling are limited resources and are the key parameters in productivity improvement. They also found that M\&S is the most suitable solution to determining facility, space, human, and schedule in supporting decision-making through "plan-do-check -act" cycles[1].

The load of resources (i.e., block stockyard, and transporters.) in the block logistics process in a shipyard influences the mid-term planning and scheduling of shipyard management. Hence, the M\&S method is used to analyze the load of block logistics process as a discrete event simulation (DES) solution before confirming the planning and scheduling.

\section{RELATED WORKS}

Much research effort has been devoted to improving manufacturing productivity based on DES for replicating processes and production lines. A complex flexible manufacturing system was built by Wu and Wysk (1989) using DES [2]. Their research expanded the scope of DES applications, which had mostly been applied to basic queuing systems.

In the study of Alfeld et al. (1998), DES was used for the shipbuilding process [3]. A unique software program that simulates the dynamic complexities of the ship construction process was described. The simulation model of the shipyard production process captures both the essential physical shipbuilding activities and management decisionmaking activities that support the physical production processes. Hence, the model was defined as a virtual shipyard. Alfeld et al. aimed to realize virtual manufacturing in the shipbuilding industry.

Shin et al. (2004) performed the production process modeling of the subassembly lines using the DES Method [4]. Lee et al. (2009) proposed a production execution planning system for panel block operations utilizing DES and simulated annealing [5]. They also suggested a systematic approach.

Krause et al. (2004) [6] used DES to test and evaluate different scenarios in investment planning, scheduling, and resource planning for supporting shipyard investment and scheduling. In a virtual shipyard environment, the cost of finding the optimum solutions and the risk related to wrong decisions in the real world can be drastically reduced.

In Korean shipbuilding, the digital shipyard based on DES was constructed by the Seoul National University with Samsung Heavy Industry in the early 2000s. (Woo et al 2014) [7].The simulations were also divided into certain cases, such as cutting shop, fabrication factory, assembly line, outdoor process, and erection. The digital shipbuilding process based on DES is shown in Fig.1.

Kim et al. (2002) applied the digital manufacturing technologies in the shipbuilding industry [8]. They presented a case study that uses the virtual assembly simulation system for shipbuilding (VASSS) and a simulationbased tool, for evaluating block erection sequence considering shipyard facilities, operational efficiency and equipment replacement time.

Steinhauer et al. (2005) [9] developed the simulation toolkit shipbuilding (STS) to enable the simulation team of Flensburger shipyard (Germany) to effectively and efficiently build and maintain simulation models of the production. With the STS simulation supporting different 
PAPER

SHIP Block Logistics Simulation BASED on Discrete Event Simulation
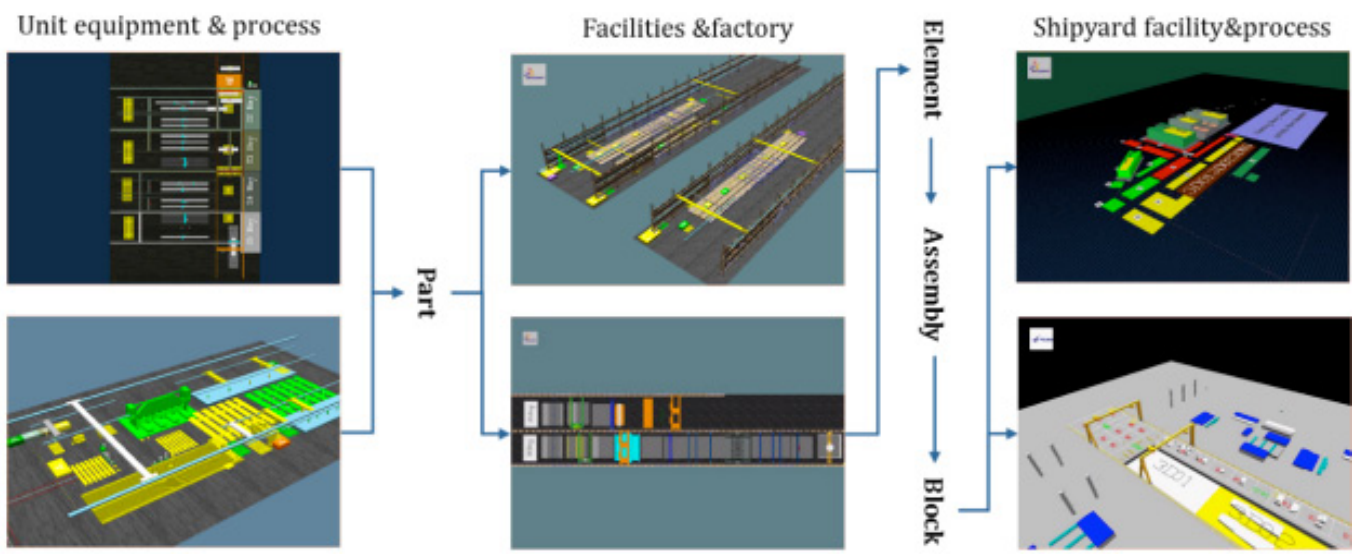

Figure 1. Digital shipbuilding process based on DES (Shin et al. 2004)

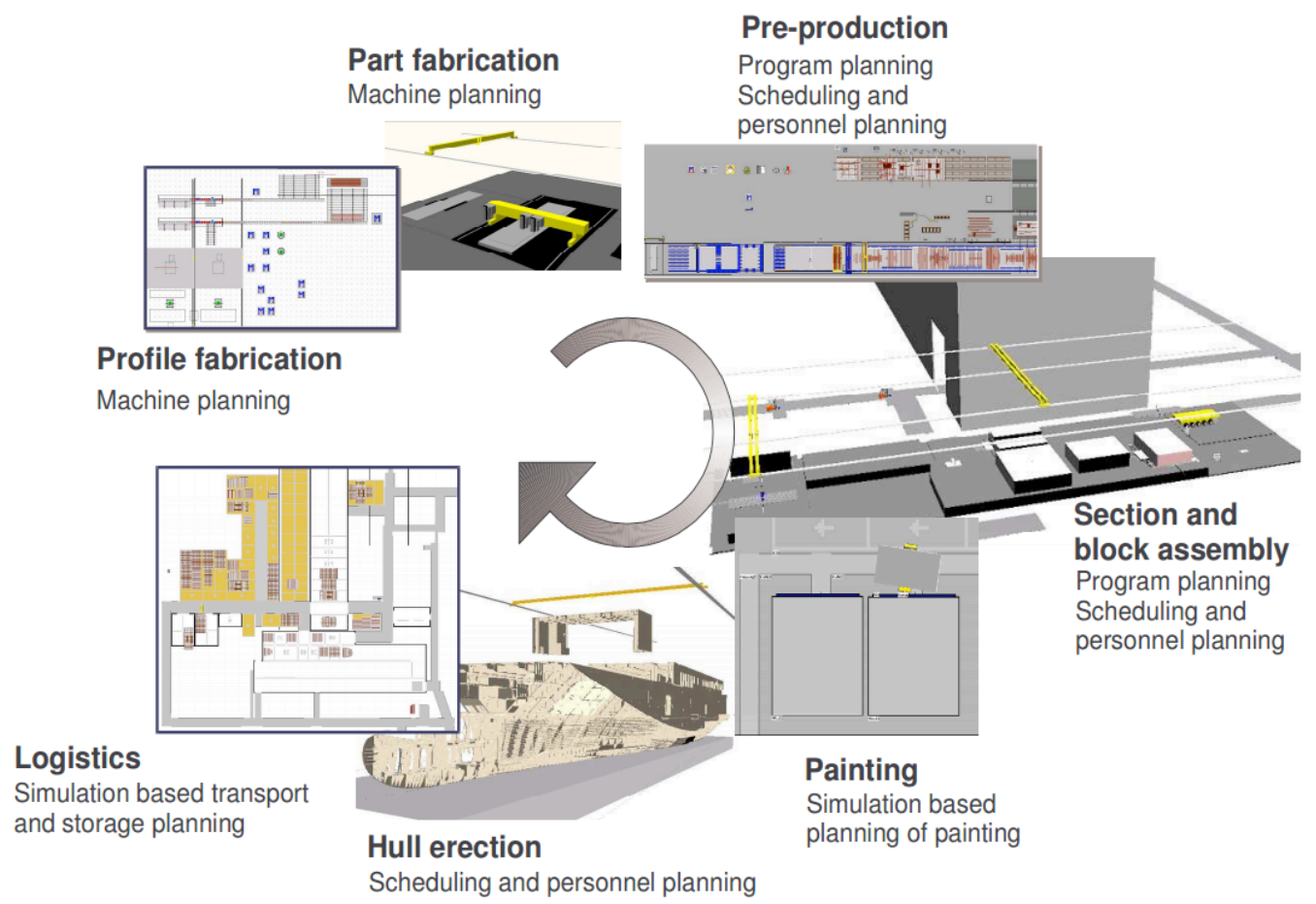

Figure 2. Simulation-aided production planning at Flensburger

areas of the production, the plan or its variations can be analyzed and verified easily. The simulation aided production planning at Flensburger and is shown in Fig.2

\section{Analysis And Simulation Modeling Of ThE SHIP BLOCK LOGISTICS SIMULATION SYSTEM}

\section{A. Shipbuilding planning process}

In the shipyard, the backward scheduling method is usually adopted to establish the block construction scheduling plan. First, the ship construction policy is made to be delivered on time as a benchmark. Erection scheduling at the dock is then determined through a comprehensive consideration of the capacity of various resources (i.e., human, space, equipment, etc.). The shipbuilding schedule plan is formulated by the backward scheduling. The AS-IS mid-term scheduling work plan is depicted in Fig. 3(a).

Such plan preparation and scheduling decision state depend solely on empirical knowledge or the know-how of experts. This situation often makes the rhythm of shipyard production incoherent and results in a serious impediment to the realization of a modern shipbuilding mode, that is, continuous, balanced, and orderly process of ship construction.

The complex discrete manufacturing system can be improved using the DES method (Banks et al. 2004 [10], Choi 2013 [11]). Manufacturing systems are generally complex discrete event systems with dynamic and complex characteristics, and shipbuilding is one such system.

As a system simulation modeling and experimental analysis technique, computer simulation can dynamically combine production resources, process data, and other information. In other words, computer simulation can fully reflect the manufacturing process and characteristics of dynamic activity for the design and operation of manufacturing system management as one method. This tool is important for the manufacturing system throughout its life cycle and can provide an integrated environment for technology, and a digital manufacturing system (Hou et al. 2001[12]). 
PAPER

SHIP Block Logistics Simulation BASED on Discrete Event Simulation

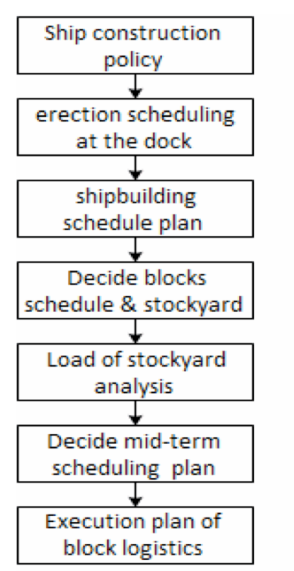

(a)

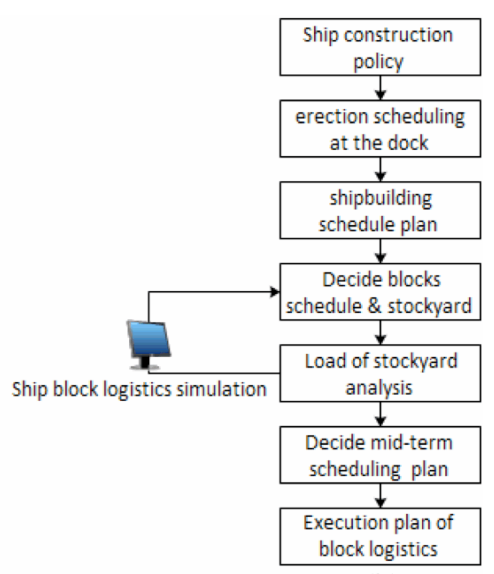

(b)

Figure 3. AS-IS (a) and TO-BE (b) mid-term scheduling work plan

\section{B. Ship block logistics}

The shipbuilding process includes few sub processes which are key events. These processes are steel cutting, sub-assembly, assembly, pre-outfitting, pre-painting, preerection, erection, and painting. In these processes, several small parts are combined into sub-blocks, giant blocks and the hull. Kim et al. (2013) [13] classified the logistics of shipbuilding according to the unit of the handled parts, as described: steel logistics, structural parts logistics and block logistics. As shown in Fig.4, steel logistics refers to iron plates and small shapes cut from the iron plate; structural parts logistics refers to small assembly parts made from the materials produced by steel logistics; and block logistics refers to small parts assembled into larger blocks. Regardless of the type of logistics, the main purpose of the logistics system is to reduce the production cost of shipbuilding by managing as efficiently as possible the space and time spent during the production process.

In the present study, we focus on block logistics to build a decision-making support for mid-term planning and scheduling.

\section{Ship block logistics}

A ship consists of hundreds of blocks, which need to be transported in the shipyard. Block logistics belongs to mid-term planning and scheduling category. Utilizing the resources of the ship's block logistics process is important in implementing medium-term planning and scheduling in shipbuilding. Prior to executing the plan, a simulation based on the DES method should be built to analyze the load of the stockyard, utilization of the road, and load of the transporter to establish optimum production scheduling. The TO-BE mid-term scheduling work plan is presented in Fig. 3(b).

This study predicts the block logistics problem in the planning stage that may occur in the production execution stage using the DES method, which can increase productivity at an early stage. The output, namely, the utilization of critical resources, such as stockyards, transporters, and roads, is discussed through the simulation. The specific forecast objectives are as follows:

1. Predict the utilization of outdoor roads and stockyards.

2. Predict the utilization of transporters and the scheduling of transporters' operations.

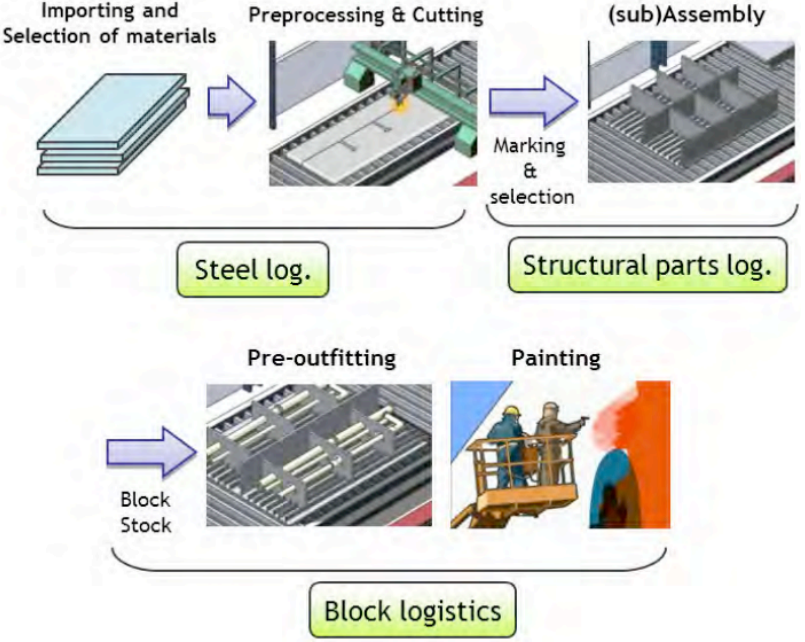

Figure 4. Classification of logistics in shipbuilding process

\section{Analysis and simulation modeling of the ship block logistics process}

Discrete event system simulation is the modeling of systems, in which the state variable changes only at a discrete set of points in time (Banks et al. 2004 [10]). DES is a simulation methodology that runs a model with a generated event and a condition change of each entity. The discrete event system is suitable for the simulation modeling of shipyard block logistics, which provides decision support to plans at an early stage of the planning and scheduling.

The Queuing Event Simulation Tool (QUEST) software, which was developed by Dassault Systems Company, is a process oriented modeling commercial software. One of the advantages of this simulation package is the possibility of reusing procedures and geometries of products and resources, which are stored in a user library (Caprace et al. 2011) [14].

Another advantage is that message boxes are shown while the simulation runs. The program contains indications of the problem elements and the type of error to help users verify the model. The activity rules defined by the simulation control language are also sufficient.

\section{1) Data collection and analysis of ship block logistics}

In this research, the product, process, resource, and schedule data-handling method is adopted for the data modeling of ship block logistics simulation. This method is available for logistics analysis, load balancing analysis, and production analysis as a typical pre-process of simulation modeling.

The related ship block logistics data are obtained from the shipbuilding planning system and the ship production department to establish the data model of ship block logistics through reconstruction data. The framework of data structuring is shown in Fig. 5.

In QUEST, the simulation model is described through physical and logical models. The physical model is a system model established by 3D graphics; the logical model is an element involved in the simulation by the basic elements (Element) and parts (Part). Part refers to an object that can flow in the QUEST model or system process; the basic elements can be divided into auxiliary elements, 
PAPER

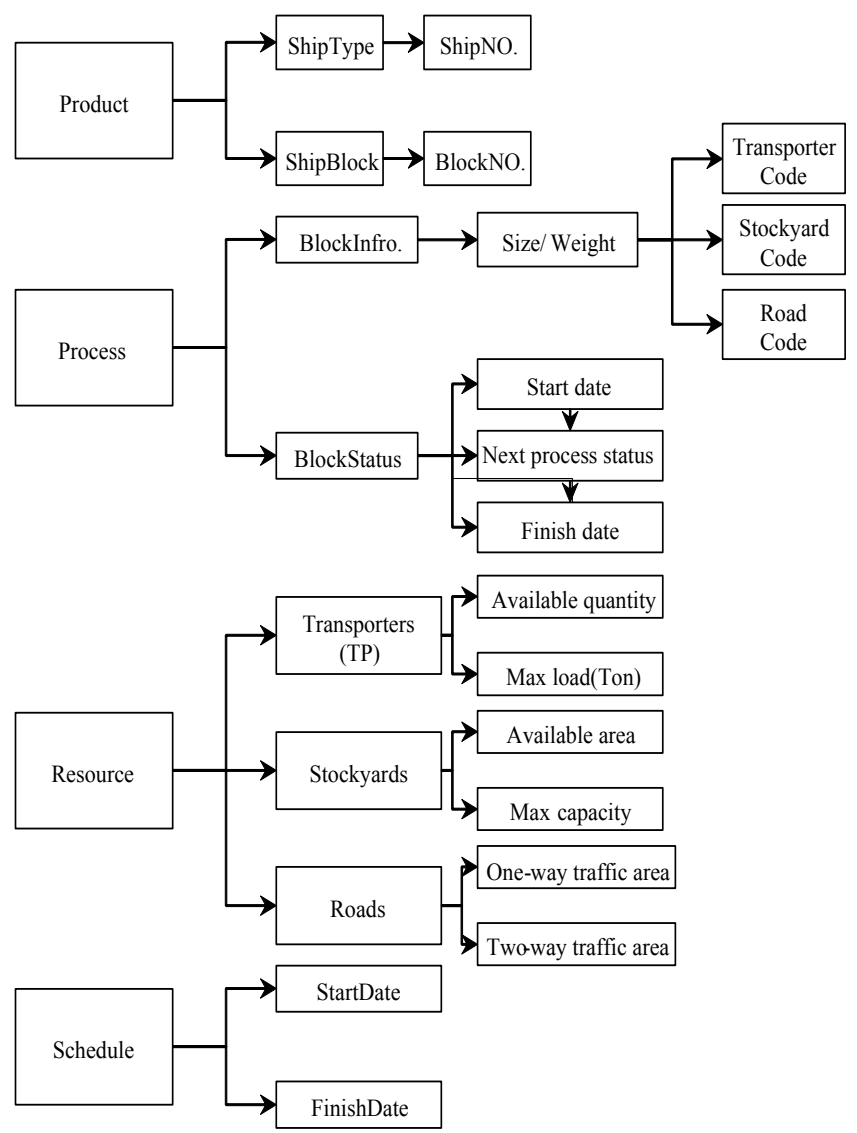

Figure 5. Framework of the data structuring for ship block logistics simulation

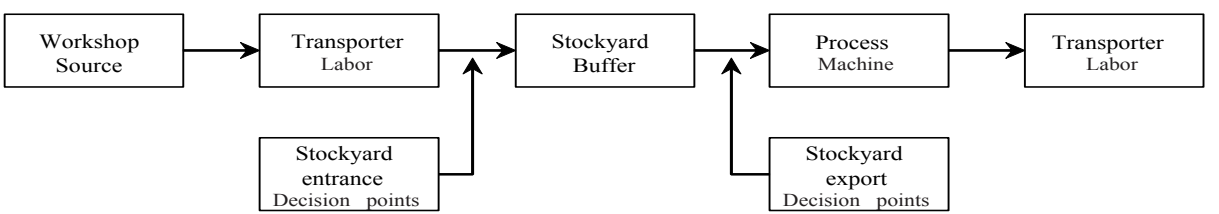

Figure 6. Assumption elements model

static elements, and material handling systems. In this study, the part is the ship block, and the basic element mainly includes the scenario of storage, transport, and handling.

2) Assumption elements model and physical modeling

The basic simulation elements, such as automated guided vehicle $(\mathrm{AGV}) /$ crane, machine, buffer, and labor are provided. Hence, these simulation elements need to be associated with the internal objects of the simulation. Through this step, the simulation elements have the same operation as the properties, which in turn enhance the reliability and credibility of the simulation model.

In the general manufacturing system, the $\mathrm{AGV}$ is used to reflect the model of the equipment for transportation, such as transporter or forklift. However, in most cases, several limitations in the AGV logic are provided that simulates the behavior of the real transportation equipment. The reason for these limitations is that several cases, such as the interference avoidance and two-way passage on the general road, exist in a real system but are not reflected in the basic built-in logic of QUEST (Fig. 6).
Therefore, a reasonable assumption is necessary. In QUEST, both AGV and labor are assumed to fix the transport path. However, the labor element can react to the two-way access road. Two entities can also be assumed to move in different directions at a fixed road without mutual interference. For this reason, the AGV logic is replaced by the labor built-in logic. At this time, the road path is planned using decision points.

Given that the dynamic simulation using QUEST mainly focuses on the analysis and calculation, building the model is relatively simple. For virtual reality scenes, a few elements of the physical model are created as shown in Fig. 7.

Based on the aforementioned method, the simulation system of the ship block logistics is built. The simulation system of the ship block logistics of the target shipyard is presented in Fig.8. Notably, the simulation model and the equipment resources of the shipyard block logistics are in good agreement.

\section{Simulation RESUlts}

The system can be realized after the simulation model is built, and the simulation results are presented in the 
PAPER

ShiP Block Logistics Simulation BASEd on DisCRETE Event Simulation

document. In QUEST, several standard reports are provided. The simulation engineer can also customize these reports by themselves according to the actual needs of the project. Separate tables are provided for each element. The statistics can be dynamically displayed in graph format, along with the simulation, and can be constantly updated. These charts display the status changes when the model runs, provided the mathematical basis for the analysis is given.

\section{A. Analysis of the utilization of outdoor roads and stockyards}

In this study, an actual shipyard is selected for the ship block logistics simulation. The layout of 11 main roads (ROAD1 to ROAD 11) and 6 stockyards (S1 to S6) are presented in Fig. 9.

Table I shows the load of the roads. During the simulation, ROAD5 is the busiest road and is even overloaded. Hence, in the early planning stage, ROAD5 should be avoided as the moving path for other transport equipment.

Table II shows the simulation result of the utilization of stockyards. The utilization of stockyards has the same work attributes (i.e., SY2 and SY5, SY3 and SY6). The results of SY2 and SY5 are $65.51 \%$ and $73.21 \%$, respectively. The results of SY3 and SY6 are $80.66 \%$ and $85.32 \%$, respectively. A small difference observed between these stockyards reveals that the work package in this plan is balanced. However, a huge gap is found between SY4 and SY1, with $90.57 \%$ and $68.53 \%$, respectively. Thus, in the actual plan, this condition needs to be considered to reduce the workload of SY4; the workload for SY1 can be increased to balance the load.

\section{B. Prediction of the utilization of transporters and the scheduling of transporters' operations}

The transporter is one of the most important logistics equipment. Therefore, the utilization of transporters must be analyzed. Tonnage transporters are classified into the following three types according to their maximum transportation capacity: 300-, 400-, and 900-ton transporters. Table III indicates that the planning and scheduling of transporters is generally balanced and reasonable. However, in the case of the 300-ton transporters, the workload of 300_C transporter is too low. Therefore, balancing the workload of this transporter needs to be considered in the actual production.

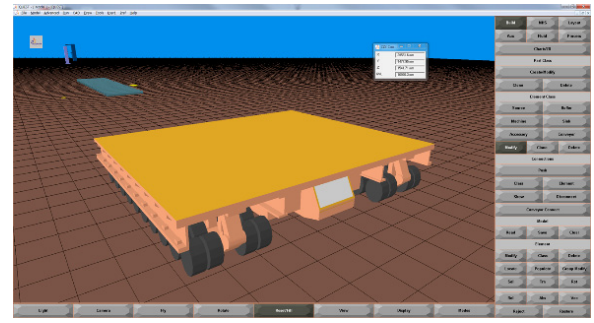

(a)Transporter

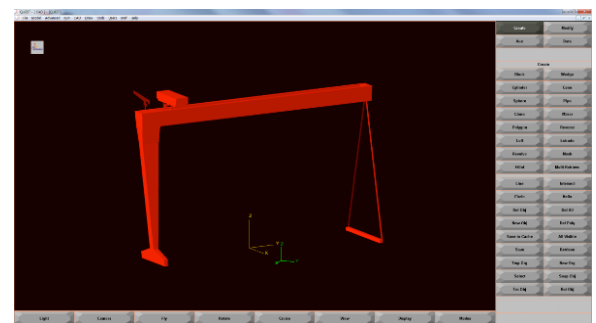

(b) Crane

Figure 7. Physical modeling of the ship block logistics simulation

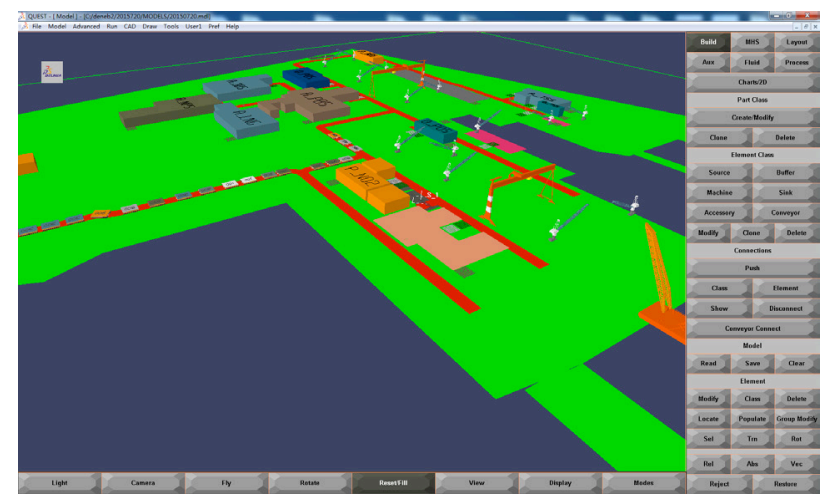

Figure 8. Simulation system of the ship block logistics

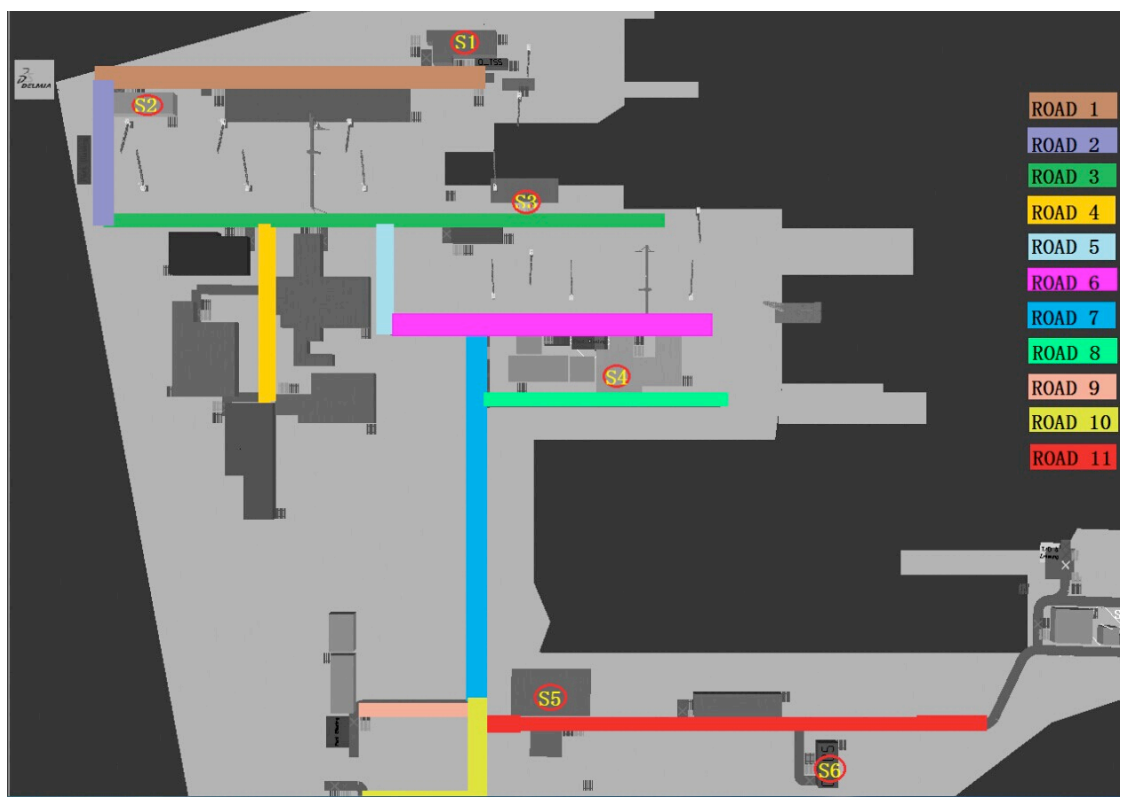

Figure 9. Layout of roads and stockyards 
PAPER

TABLE I. UTILIZATION OF STOCKYARDS

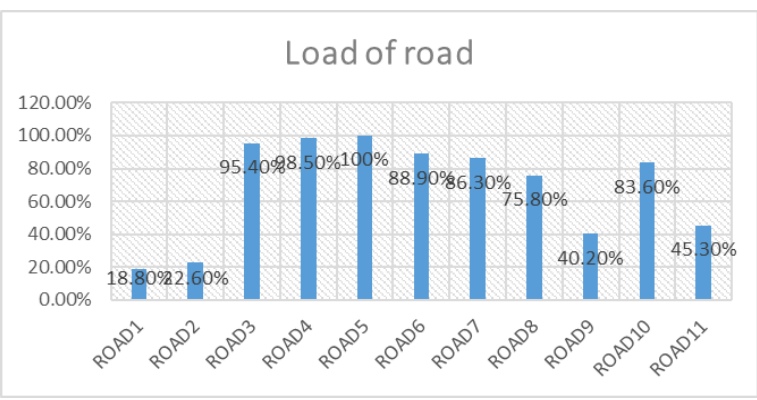

TABLE II. SIMULATION RESULTS OF THE UTILIZATION OF STOCKYARDS

\begin{tabular}{|l|l|l|}
\hline Name & Utilization/\% & Attributes \\
\hline Stockyard 1(SY1) & 68.53 & Painting \\
\hline Stockyard 2( SY2) & 65.51 & Polishing/ finishing \\
\hline Stockyard 3( SY3) & 80.66 & Outfitting \\
\hline Stockyard 4( SY4) & 90.57 & Painting \\
\hline Stockyard 5( SY5) & 73.21 & Polishing/ finishing \\
\hline Stockyard 6( SY6) & 85.32 & Outfitting \\
\hline
\end{tabular}

TABLE III. PREDICTION OF THE UTILIZATION OF TRANSPORTERS

\section{Utilization of transporters(\%)}

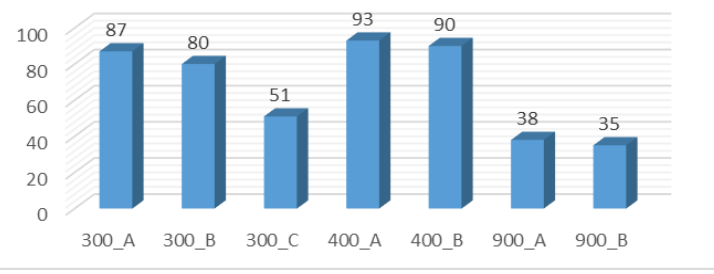

\section{CONCLUSIONS}

Shipbuilding planning mainly depends on the experience of experts. Occasionally, the plan is unreasonable, which negatively influences the balance of shipbuilding and the increase in productivity. DES is a good solution in evaluating in advance, that is, prior to deciding the plan. The simulation model of ship block logistics is built and proven to be an effective means of forecasting to obtain an optimal plan of reducing production operating costs. The result shows that this simulation system is feasible and instructive to shipbuilding.

\section{ACKNOWLEDGEMENT}

This work is supported in part by the scholarship from China Scholarship Council (CSC). The authors would like to express their sincere gratitude to the supporter.

\section{REFERENCES}

[1] Lee, Dong Kun, et al. "Simulation-Based Work Plan Verification in Shipyards." Journal of Ship Production and Design vol.30, no.2, pp. 49-57, 2014. http://dx.doi.org/10.5957/JSPD.30.2. 130032

[2] Wu, Szu-Yung David, and Richard A. Wysk. "An application of discrete-event simulation to on-line control and scheduling in flexible manufacturing." The International Journal of Production Research vol.27, no.9, pp. 1603-1623, 1989. http://dx.doi.org/ $\underline{10.1080 / 00207548908942642}$
[3] Alfeld, Louis E., Colleen S. Pilliod, and JAMES R. WILKINS. "The virtual shipyard: a simulation model of the shipbuilding process."Journal of Ship production vol.14, no.1, pp. 33-40, 1998.

[4] Shin, Jong Gye, et al. "A modeling and simulation of production process in subassembly lines at a shipyard." Journal of Ship Production vol.20, no.2, pp. 79-83, 2004.

[5] Lee, Kwangkook, Jong Gye Shin, and Cheolho Ryu. "Development of simulation-based production execution system in a shipyard: a case study for a panel block assembly shop." Production Planning and Control vol.20, no.8, pp. 750-768, 2009. http://dx.doi.org/10.1080/09537280903164128

[6] Krause, Matthias, et al. "Discrete event simulation: An efficient tool to assist shipyard investment and production planning." Journal of Ship Production vol.20, no.3, pp. 176-182, 2004.

[7] Woo, Jong Hun, and Young Joo Song. "Systematisation of ship production management and case study for ship block assembly factory." International Journal of Computer Integrated Manufacturing vol.27, no.4, pp. 333-347, 2014. http://dx.doi.org/10.1080/ 0951192X.2013.800237

[8] Kim, Hongtae, et al. "Applying digital manufacturing technology to ship production and the maritime environment." Integrated Manufacturing Systems vol.13, no.5, pp. 295-305, 2002. http://dx.doi.org/10.1108/09576060210429748

[9] Steinhauer, D. "SAPP-simulation aided production planning at Flensburger."Proceedings of COMPIT. pp.391-398, 2005.

[10] Banks, J., J. S. Carson, and B. L. Nelson. DM Nicol, DiscreteEvent System Simulation. Englewood Cliffs, NJ, USA: Prentice hall, 2004.

[11] Choi, Byoung Kyu, and Donghun Kang. Modeling and Simulation of Discrete Event Systems. John Wiley \& Sons, 2013. http://dx.doi.org/10.1002/9781118732793

[12] Hou, Yang, et al. "Simulation-based manufacturing system object modeling."COMPUTER INTEGRATED MANUFACTURING SYSTEMS-BEIJING- vol.7, no.5, pp. 42-46, 2001.

[13] Kim, Misun, et al. "Development of a Mobile Block Logistics Simulation System for Ship and Offshore Structures."The Twentythird International Offshore and Polar Engineering Conference. International Society of Offshore and Polar Engineers, 2013.

[14] Caprace, Jean-David, et al. "Discrete event production simulation and optimisation of ship block erection process." 10th International Conference on Computer Applications and Information Technology in the Maritime Industries.K. Elissa, "Title of paper if known," unpublished, 2011.

[15] Lim, Wee Teck, et al. "Implementation of Shape-Based Matching Vision System in Flexible Manufacturing System." Journal of Engineering Science and Technology Review vol.3, no.1, pp. 128135, 2010.

[16] Song, Young-Joo, Jong-Hun Woo, and Jong-Gye Shin. "Research on systematization and advancement of shipbuilding production management for flexible and agile response for high value offshore platform." International Journal of Naval Architecture and Ocean Engineering vol.3, no.3, pp. 181-192, 2011. http://dx.doi.org/10.3744/JNAOE.2011.3.3.181

\section{AUTHORS}

Wang Chong (corresp. author) is a Ph.D Candidate student in the Key Laboratory of High Performance Ship Technology of Wuhan University of Technology, Hubei, China. (e-mail: chriswang@whut.edu.cn.).

Mao Yunsheng is a professor in Wuhan University of Technology, Hubei,China. (e-mail: Ysmao@163.com).

Xiang Zuquan is an associate professor in Wuhan University of Technology, Hubei, China. (e-mail: zuquan_xiang@163.com).

Zhou Yongqing is a lecturer in Wuhan University of Technology, Hubei, China (yong_qing@whut.edu.cn).

This work is supported in part by the scholarship from China Scholarship Council (CSC) under the Grant CSC NO.201406950021. Submitted 07 July 2015. Published as resubmitted by the authors 23 October 2015. 